\title{
НАПРАВЛЕНИЯ РАЗВИТИЯ ЭКОНОМИКИ ЗАМКНУТОГО ЦИКЛА В УСЛОВИЯХ НОВОЙ ЦИФРОВОЙ ПАРАДИГМЫІ ${ }^{1}$
}

\section{DIRECTIONS OF DEVELOPMENT OF THE CIRCULAR ECONOMY \\ IN THE CONDITIONS OF THE NEW DIGITAL PARADIGM}

\section{A. Shinkevich \\ L. Gorbach \\ S. Bashkirtseva}

Summary. The article substantiates the relevance of the transformation of industrial and socio-economic processes towards the development of modern nature-saving technologies in conditions of increasing environmental stress as a result of the dominance of the traditional linear production model. A modern trend towards stabilizing this situation has become the introduction of the principles of a closed-loop economy, the efficiency of which is increased due to the digitalization of business processes. The purpose of this study is to study the key directions of the development of the circular economy in Russia and the impact of digital technologies on these processes.

Keywords: circular economy, recycling, innovations, digital technologies, innovative business models.
Шинкевич Алексей Иванович

Д.э.н., д.т.н., профессор, Казанский национальный исследовательский технологический университет ashinkevich@mail.ru

Горбач Людмила Анатольевна

К.э.н., дочент, Казанский национальный исследовательский технологический университет ludochka2904@mail.ru

Башкириева Светлана Анатольевна

К.э.н., доцент, Казанский национальный исследовательский технологический университет bashkirceva_s@kstu.ru

Аннотация. В статье обосновывается актуальность трансформации производственных и социально-экономических процессов в сторону освоения современных природосберегающих технологий в условиях повышения нагрузки на окружающую среду как результат господства традиционной линейной производственной модели. Современным трендом на пути стабилизации данной ситуации стало внедрение принципов экономики замкнутого цикла, эффективность развития которой повышается благодаря цифровизации бизнес-процессов. Целью данного исследования следует назвать изучение ключевых направлений развития циркулярной экономики в России и воздействие цифровых технологий на эти процессы.

Ключевые слова: циркулярная экономика, рециклинг, инновации, цифровые технологии, инновационные бизнес-модели.

наблюдаем рост дефицита сырьевых и энергетических ресурсов, усиливающееся загрязнение окружающей среды, в том числе за счет выбросов парниковых газов, активное загрязнение мирового океана, значительное возрастание площадей, занятых полигонами производственных и бытовых отходов и т.д., что в конечном итоге приводит к необратимым изменениям климата, создает значительную нагрузку на окружающую среду и требует трансформации производственных и социально-экономических процессов в сторону освоения современных природосберегающих технологий.

Согласно сведениям официальной статистики, в минувшем году в России было зафиксировано рекордное количество случаев высокого и экстремально высокого загрязнения воздуха (число случаев за первые 9 ме- 
сяцев 2020 г. в 3 раза превысило показатели 2019 года (171 случай против 61 соответственно) и в 7 раз показатели 2015 года (171 случай против 24 соответственно). Экстремально высоким считается загрязнение, при котором концентрация одного или нескольких вредных веществ в 20-29 раз превышает предельно допустимую при условии сохранения указанного уровня более двух суток, либо 30-49 раз при сохранении этого показателя в течение 8 часов и более [1].

Предположения относительно возможного сокращения негативного воздействия на окружающую среду в период пандемии Covid-19, как показывает практика, не оправдались, поскольку основные производственные мощности продолжали функционировать, а вопросы контроля экологичности производственных процессов отошли на второй план.

Несмотря на общемировые тенденции, растут выбросы парниковых газов (+6\% за 3 года), в первую очередь за счет энергетики (+11\%) и промышленного производства (+5\%). Особенно остро проявляет себя проблема формирования промышленных и бытовых отходов, единой программы утилизации которых в отечественной практике пока не выработано. Их количество возросло с 2015 года на 53\% и составило по итогам 2019 года 7,7 млрд. тонн, из которых только половина (3,8 млрд. тонн) была утилизирована и обезврежена [2]. Более частыми способами борьбы с отходами в отечественной практике мы наблюдаем их сжигание и хранение на мусорных полигонах и свалках ТБО.

Альтернативным вариантом и новой парадигмой промышленного и социально-экономического развития с учетом перечисленных негативных тенденций во всем мире становится концепция циркулярной экономики, основанная на модели, построенной по принципу «take, make, reuse», то есть «бери, производи, используй повторно». Переход к экономике замкнутого цикла может позволить сократить потребление природных ресурсов и энергии, минимизировать количество отходов, обеспечить снижение промышленных выбросов и их утилизацию.

Кроме того, внедрение циркулярной экономики подразумевает под собой достижение ряда социально-экономических эффектов, среди которых следует выделить:

1. сокращение затрат на сырье и материалы;

2. более рациональное использование продукции, следовательно, снижение расходов;

3. сокращение экологических платежей, налогов и штрафов;

4. снижение ресурсоемкости производства;

5. сокращение затрат на утилизацию отходов;
6. формирование дополнительной прибыли от реализации побочной продукции или отходов; и т.д.

Следует сказать, что перечисленные эффекты имеют отношение в основном к микроэкономическим системам, то есть к деятельности предприятий. Однако на макроуровне ожидаемый эффект также значителен. В частности, предполагается расширение рынка труда, появление новых рабочих мест в сфере переработки отходов и сервисов вторичного использования, ремонта и обратной логистики, снижение социальной напряженности за счет развития новых моделей рационального потребления, в перспективе можно ожидать и повышения уровня жизни и здоровья граждан, и т.д. [3]

Вопросы влияния процессов производства и потребления на окружающую среду еще в середине XX века завладели умами ученых. Так, в 1966 г. американский экономист К. Боулдинг впервые в своем труде поднимает вопрос взаимодействия экономики и экологии, отмечая, что человеческое общество не осознает степени значимости существующей проблемы, и, учитывая все возрастающие масштабы человеческой деятельности, ожидать улучшения ситуации не имеет смысла. К. Боулдинг видел решение данной проблемы в увеличении жизненного цикла товаров или возможной повторной их переработке, то есть впервые обратил внимание на необходимость смены производственной парадигмы и формирования экономики замкнутого цикла [4].

Сам термин «циркулярная экономика» появился в науке сравнительно недавно, в 2005 году, однако активный научный и практический интерес к этой категории в России проявился лишь к 2014 году, который стал отправной точкой в формировании теоретико-методологической базы по данному направлению. Изначально это были научные исследования в сфере промышленной экологии, теории промышленных экосистем, теории социоэкологических систем, концепции «нулевых выбросов» и т.д. Сегодня часто проблему развития циркулярной экономики рассматривают в контексте инновационного развития и трансформационных процессов экономических систем, однако следует учитывать междисциплинарный характер данного научного направления [3]. Среди авторов, исследующих представленную научную область, следует выделить Ратнер С.В., Пахомову Н.В., Рихтер К.К., Хаас В., Андерсена М., Калякину И.М., Мясникову О.В., Сахбиеву А.И., Шинкевича А.И., Малышеву Т.В. и др.

Единой и универсальной трактовки термина «циркулярная экономика» на сегодняшний день не выработано. В материалах Двенадцатой сессии Комитета по инновационной деятельности, конкурентоспособности и государственно-частным партнерствам Европейской 
экономической комиссии ООН, прошедшей в Женеве в марте 2018 года, понятие «экономика замкнутого цикла» истолковано, как система, в которой ценность товаров, материалов и ресурсов сохраняется в экономике как можно дольше, где отходы рассматриваются как активы или ресурс. Согласно определению Фонда Элен Макартур, «она является восстановительной или регенеративной и направлена на улучшение состояния и сохранение природного капитала, использование ресурсов с оптимальной отдачей и минимизацию системных рисков путем регулирования запасов и возобновляемых потоков» [5].

Совокупность дефиниций категории «экономика замкнутого цикла» можно разделить на две группы. В первой авторы делают акцент на обеспечении замкнутого оборота материальных ресурсов и сокращении введения в него новых. Во второй группе трактовка выходит за пределы задачи управления материальными ресурсами и затрагивает различные аспекты потребительского поведения. В целом следует согласиться с мнением, что циркулярная экономика - модель экономического развития, которая направлена на ресурсосбережение, регенеративное экологически чистое производство и ответственное потребление.

Чаще всего, характеризуя циркулярную экономику, упоминают о ее характерных свойствах, обеспечивающих замкнутый характер производственных процессов и продление жизненного цикла продукции благодаря повторному использованию, повторному производству или восстановлению, переработке и утилизации продукции и бытовых отходов и отходов производства. При этом, в зависимости от уровня экономической системы, в рамках которой рассматриваются основные принципы циркулярной экономики, составными элементами данной производственной модели можно назвать «чистое производство», экодизайн (продвинутая функциональность, модульная конструкция, повторное использование частей, восстановление), дематериализацию (предоставление услуг в электронном формате), «зеленые» цепи поставок, обратную логистику, системы управления ресурсами и отходами и т.д. [3]

Сущность циркулярной экономики можно описать тремя ключевыми характеристиками.

1. Замкнутые циклы. Экономика в таком случае функционирует по примеру экосистемы, где отходы становятся сырьем для производства нового продукта. Производители принимают свою продукцию после использования, ремонтируют ее для нового срока службы.

2. Возобновляемая энергия (энергия должна использоваться максимально эффективно за счет возобновляемых источников энергии).
3. Системное мышление. В процессе реализации экономической деятельности все участники должны принимать во внимание последствия своих действий в краткосрочной и долгосрочной перспективе, а также их влияние на цепочку создания стоимости. Следовательно, помимо технологических преобразований, переход к циркулярной экономике предполагает и социальные трансформации, изменение моделей потребительского поведения.

Нормативно-правовое сопровождение процесса становления циркулярной экономики в России обеспечивает совокупность федеральных законов. В частности, Федеральный закон «Об охране окружающей среды», «Об отходах производства и потребления», «Об охране атмосферного воздуха», «Об особо охраняемых природных территориях», «Об экологической экспертизе» и т.д. Они определяют направления государственной политики в области природопользования и охраны окружающей среды, и предусматривают возможности для внедрения современных технологий.

Актуальность экологической проблемы предопределила и разработку ряда стратегических программных документов, определяющих ключевые направления развития с учетом принципов циркулярной экономики. Так, в 2018 году был принят национальный проект «Экология» сроком действия до 2025 года, среди ключевых задач которого - снижение выбросов опасных загрязняющих веществ и создание устойчивой системы обращения с твердыми коммунальными отходами, в том числе обеспечивающей сортировку отходов в объеме $100 \%$ и снижение объема отходов, направляемых на полигоны, в 2 раза. Ранее о необходимости уменьшения экологического ущерба, связанного с захоронением твердых бытовых отходов, в официальных документах заговорили еще в 2016 году в приоритетном федеральном проекте «Чистая страна» сроком действия по 2025 год включительно.

Аналогичные задачи были прописаны и в перечне инициатив социально-экономического развития России до 2030 года, утвержденного в рамках Программы стратегического развития России в октябре 2021 года. В числе важнейших направлений данного проекта представлена и «Экология», которая предполагает реализацию четырех ключевых инициатив: переработку отходов, бережную добычу минеральных ресурсов, снижение выбросов парниковых газов и ликвидацию опасных свалок и аварийных объектов.

Однако следует заметить, что на сегодняшний день в России перерабатывают только 9\% мусора, и динамика роста данного показателя за 3 года действия упо- 
мянутого национального проекта составила лишь $2 \%$, а темпы роста промышленных отходов с каждым годом становятся все выше. По состоянию на ноябрь 2020 года в стране насчитывалось 8323 свалки, в том числе 916 на территории городских округов. Современные тенденции свидетельствуют о том, что в перспективе появится необходимость выделения дополнительных площадей под полигоны, учитывая их загруженность на сегодняшний день. При этом, согласно паспорту проекта «Чистая страна», надежда в основном возлагается не на мусороперерабатывающие, а на мусоросжигательные заводы, которые должны снизить объем размещения отходов на свалках и достичь модели «нулевого захоронения».

В октябре 2021 года утверждение Правительством РФ получила и Стратегия социально-экономического развития России с низким уровнем выбросов парниковых газов до 2050 года, в которой поставлена цель достижения углеродной нейтральности при устойчивом росте экономики. Среди мероприятий по декарбонизации заявлено оказание мер поддержки в отношении внедрения, тиражирования и масштабирования низкои безуглеродных технологий, стимулирование использования вторичных энергоресурсов, изменение налоговой, таможенной и бюджетной политики, развитие зелёного финансирования, меры по сохранению и увеличению поглощающей способности лесов и иных экосистем, поддержка технологий улавливания, использования и утилизации парниковых газов. Таким образом, в рамках целевого сценария станет возможным рост экономики при уменьшении выбросов парниковых газов. К 2050 году их чистая эмиссия должна снизиться на $60 \%$ от уровня 2019-го и на $80 \%$ от уровня 1990 года. Дальнейшая реализация этого сценария позволит России достичь углеродной нейтральности к 2060 году.

Необходимо отметить, что построение циркулярной экономики невозможно без фундаментальных преобразований всех этапов производственно-сбытовой цепочки - от дизайна изделий и технологий их производства до новых бизнес-моделей, новых способов сохранения природных ресурсов (продления срока службы продукции) и превращения отходов в ресурс (переработка), новых форм потребительского поведения, обновления стандартов и практики, и т.д. Следовательно, неизбежна трансформация всех социально-экономических и производственных процессов, в результате которых возможно распространение «замкнутых» циклов в традиционные производственные и бизнес-модели.

В качестве инновационных бизнес-моделей, описывающих функционирование циркулярной экономики, многие авторы выделяют следующие.
1. Циркулярные поставки, где ограниченные ресурсы заменяются на полностью возобновляемые.

2. Восстановление ресурсов, предполагающее технологические инновации по восстановлению и повторному применению ресурсов и снижению отходов.

3. Создание платформ для обмена и совместного использования товаров, жилья, транспорта и т.д.

4. Продление жизненного цикла продукции за счет ремонта, модернизации, реконструкции и восстановления.

5. Модель «продукт как услуга», при которой клиенты арендуют продукцию с оплатой по факту использования, и т.д. [6]

В соответствии с приведенными бизнес-моделями происходит трансформация производственных и логистических процессов, предусматривающая формирование новых тенденций и принципов. Так, в частности, с целью минимизации объемов производства и исключения возможности перепроизводства особую актуальность приобретает кастомизация, то есть изготовление продукции по индивидуальным требованиям потребителя под конкретный заказ. Широкую популярность обретает система технического обслуживания восстановительного ремонта продукции и ее отдельных компонентов, обеспечивающая диагностику, ремонт, модернизацию продукции до определенного уровня производительности. Кроме того, предполагается расширение возможностей совместного потребления продукции, предоставления ее во временное пользование, повторное использование, восстановление и т.д. [6]

Следует сказать, что реализация названных принципов и тенденций наилучшим образом может быть осуществлена за счет использования цифровых технологий. Цифровизация может стать катализатором и мощным инструментом обеспечения цикличности продуктов, повышая эффективность управления ресурсами.

Речь идет о совокупности технологий, выступающих фундаментом четвертой промышленной революции и Индустрии 4.0.: Интернет вещей (IoT), аддитивные технологии (3D печать), большие данные (Big data), технологии виртуальной и дополненной реальности, искусственный интеллект и т.д. Эти технологии в корне меняют способы организации деятельности компаний, предоставляя возможность интеграции усилий разных хозяйствующих субъектов в рамках перехода к новой экономической парадигме, и создают условия для эффективного мониторинга движения материальных потоков и совместного использования продукции. 
Например, благодаря технологии Интернет вещей (loT) может быть обеспечено автоматическое отслеживание местоположения и мониторинг природного капитала. Производители, используя данные технологии, имеют возможность получать больше данных как о производстве, так и об использовании продуктов.

Значимую роль в процессе формирования экономики замкнутого цикла играет роботизация, которая успешно может быть использована в решении различных задач, например, по сортировке мусора, его переработке, сокращая удельные затраты и снижая вероятность ошибок.

Технологии больших данных (Big data) позволяют осуществлять сбор и обработку информации о движении материальных потоков (отходов и ресурсов) в режиме реального времени. Кроме того, эти технологии способны обеспечить цифровой анализ данных для прогнозирования состояния и износа продукта, сокращения времени простоя производства, планирования технического обслуживания и оптимизации энергопотребления $[7,8]$.

Благодаря цифровым технологиям возможно обеспечить экономическую систему необходимой инфраструктурой, в частности речь идет о создании платформ для организации совместного использования продукции. Например, ранее упомянутая система каршеринга. Таким же образом может быть обеспечена организация обратной логистики, задача которой состоит в изучении формирования возвратных потоков и управление ими, обеспечивая планирование и контроль движения сырья, материалов, полуфабрикатов и готовой продукции.

Снижению излишков продукции и перепроизводству способствует также взаимодействие потребителей через различные программы и социальные сети, благодаря которым вещи приобретают вторую жизнь, что тоже стало возможным благодаря цифровизации. Аналогичную задачу сокращения объема производства и излишков продукции может решить и повсеместное внедрение аддитивных технологий, более известных как 3D-печать, которые позволяют производить продукты по запросу в нужном количестве. По такому же принципу работает и система краудфандинга, продвигающая идею совместного, коллективного вложения средств для производства продукции, выявляя таким образом интерес потребителя к конкретным товарам и их характеристикам еще на этапе разработки и сокращая производство невостребованной продукции.

Позитивное влияние на обеспечение экологичности производственных процессов создается и за счет снижения потребления ресурсов при осуществлении административно-управленческих функций благодаря переводу документооборота в цифровой формат.

Следует отметить, что в современныхусловияхпринципы циркулярной экономики начинают все больше закрепляться в сознании как отдельных производителей, так и всего общества. И уже сегодня можно привести ряд примеров внедрения данной парадигмы в производственную деятельность крупных компаний. Например, переход на альтернативные источники энергии анонсировали такие компании как IKEA и Google. Компания North European Bio Tech Оу (Финляндия) широко освоила технологию производства возобновляемых топлива и энергии из сельскохозяйственных остатков (кукурузные початки, шелуха, листья и стебли) при производстве целлюлозного биоэтанола. Данная технология обеспечивает компанию новым источником дохода, одновременно сокращая выбросы в окружающую среду.

Мировой лидер алюминиевого проката Novelis организовал сотрудничество c Ford Motor Company, перестроив производственные процессы с целью организации замкнутого цикла переработки алюминия в автомобильной промышленности. Это позволяет экономить до 95\% энергии по сравнению с его производством и сокращает выбросы парниковых газов так же на 95\%. Согласно отчету об устойчивом развитии компании Ford Motor Company за 2017/2018 гг., около 300 деталей для автомобилей производится в компании из возобновляемых материалов (каучук, хлопок, древесина и т.д.)

Широкую популярность получила бизнес-модель услуг, предполагающая предоставление возможности использования товара или функцию продажи, вместо самого товара. Например, компания Phillips при реализации подобной бизнес-модели предоставляет услуги освещения вместо осветительных приборов. Компания Xerox продает ксерокопии, а не копировальную технику, и в перспективе стремиться к возврату оборудования по истечению сроков его эксплуатации для последующей переработки. К этой же модели можно отнести предоставление в аренду, то есть совместное использование отдельных продуктов (автомобилей, техники, оборудования и даже одежды, как поступила компания Mud Jeans). Данная модель получила название C2C, в рамках которой потребители могут активно взаимодействовать друг с другом посредством онлайн платформ, таких как сервисы BlaBlaCar, Airbnb, RelayRides и другие [8].

Таким образом, трансформация экономической системы России в сторону развития экономики замкнутого цикла на современном этапе является объективной необходимостью, продиктованной возрастающим дав- 
лением на окружающую среду. При этом важным условием, способным обеспечить успешность инициатив в области экологизации производственных процессов, следует назвать внедрение цифровых технологий, которые способны повысить эффективность управления ресурсами и принятие решений, обеспечить накопление знаний, облегчить анализ и автоматизировать сбор, обработку информационных потоков, отслеживание местоположения ресурсов и прогностическую деятельность предприятий.

\section{ЛИТЕРАТУРА}

1. В России поставлен рекорд по загрязнению воздуха за 16 лет. [Электронный ресурс].

2. Охрана окружающей среды в России. 2020: Стат. сб. / Росстат.- М.: 2020.- 113 с.

3. Ратнер С.В. Циркулярная экономика: теоретические основы и практические приложения в области региональной экономики и управления / С.В. Ратнер // Инновационная экономика. — 2018.—№ 9.—С. 29-37.

4. Пахомова Н.В. Переход к циркулярной экономике и замкнутым цепям поставок как фактор устойчивого развития / Н.В. Пахомова, К.К. Рихтер, М.А. Ветрова // Вестник Санкт-Петербургского университета.— № 2.- 2017.— С. 244-268.

5. Материалы Двенадцатой сессии Комитета по инновационной деятельности, конкурентоспособности и государственно-частным партнерствам Европейской экономической комиссии 0ОН [Электронный ресурс]. - Режим доступа: https://unece.org/fileadmin/DAM/ceci/ documents/2018/CICPPP/ Official_documents/ECE_CECl_2018_3_1802056R.pdf, свободный.

6. Мясникова 0.В. Цифровая трансформация логистических систем дистрибуции при переходе на модели экономики замкнутого цикла / 0.В. Мясникова // Экономика. Управление. Инновации. — 2018. - № 2. - С. 3-10.

7. Аванесян Э.А. Экономика замкнутого цикла и цифровизация: современные тренды и перспективы / Э.А. Аванесян, А.И Сахбиева, И.М. Калякина // Альманах «Крым». — 2021. — № 25.- - С. 41-46.

8. Перелет Р.А. Роль информационных технологий при переходе к экономике замкнутого цикла / Р.А. Перелет // Образовательные ресурсы и технологии. - 2019. - № 3.—C. 74-82.

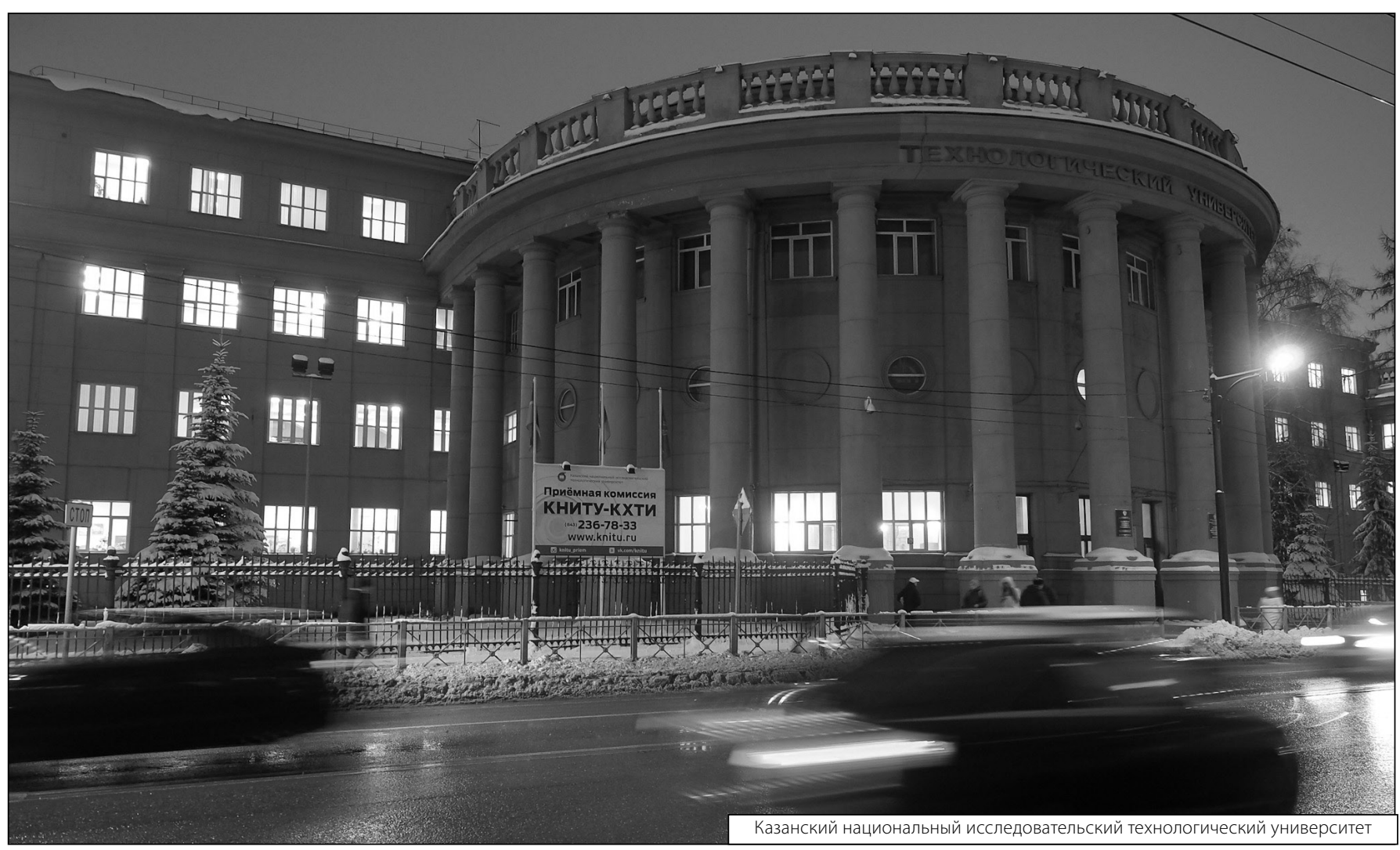

